\title{
The cognitive impact of anticholinergics: A clinical review
}

This article was published in the following Dove Press journal:

Clinical Interventions in Aging

II May 2009

Number of times this article has been viewed

\author{
Noll Campbell ${ }^{4}$ \\ Malaz Boustani ${ }^{1,2,3}$ \\ Tony Limbil' \\ Carol Ott ${ }^{4,5}$ \\ Chris Fox $6,7,8$ \\ lan Maidment ${ }^{6,7}$ \\ Cathy C Schubert ${ }^{3}$ \\ Stephanie Munger ${ }^{1,2}$ \\ Donna Fick ${ }^{9,10}$ \\ David Miller ${ }^{3}$ \\ Rajesh Gulati"
}

'Regenstrief Institute, Inc. Indianapolis, IN, USA; ${ }^{2}$ Indiana University Center for Aging Research; ${ }^{3}$ Department of Medicine, Indiana University School of Medicine, Indianapolis, IN, USA; ${ }^{4}$ Wishard Health Services, Indianapolis, IN, USA; ${ }^{5}$ School of Pharmacy and Pharmaceutical Sciences, Purdue University, West Lafayette, IN, USA; ${ }^{6}$ Kent Institute of Medicine and Health Sciences, University of Kent, Canterbury, Kent, UK; ${ }^{7}$ Kent and Medway NHS Trust, Dartford, Kent, UK; ${ }^{8}$ Postgraduate Medical Institute, University of Hull, Hull, UK; ${ }^{9}$ Penn State University School of Nursing; ${ }^{10}$ Department of Psychiatry, Penn State College of Medicine; "Indiana University Medical Group - Primary Care, Indianapolis, IN, USA

Correspondence: Malaz Boustani Regenstrief Institute, Inc, 410 West 10th Street, Suite 2000, Indianapolis, Indiana 46202-3012, USA

Tel + I 3174235633

Fax +I 3174235695

Email mboustani@regenstrief.org
Context: The cognitive side effects of medications with anticholinergic activity have been documented among older adults in a variety of clinical settings. However, there has been no systematic confirmation that acute or chronic prescribing of such medications lead to transient or permanent adverse cognitive outcomes.

Objective: Evaluate the existing evidence regarding the effects of anticholinergic medications on cognition in older adults.

Data sources: We searched the MEDLINE, OVID, and CINAHL databases from January, 1966 to January, 2008 for eligible studies.

Study selection: Studies were included if the anticholinergic activity was systematically measured and correlated with standard measurements of cognitive performance. Studies were excluded if they reported case studies, case series, editorials, and review articles.

Data extraction: We extracted the method used to determine anticholinergic activity of medications and its association with cognitive outcomes.

Results: Twenty-seven studies met our inclusion criteria. Serum anticholinergic assay was the main method used to determine anticholinergic activity. All but two studies found an association between the anticholinergic activity of medications and either delirium, cognitive impairment or dementia.

Conclusions: Medications with anticholinergic activity negatively affect the cognitive performance of older adults. Recognizing the anticholinergic activity of certain medications may represent a potential tool to improve cognition.

Keywords: anticholinergic activity, cognitive impairment, delirium, elderly

\section{Clinical scenario}

A 78-year-old Caucasian female presents to the emergency department (ED) with a chief complaint of shortness of breath, lethargy, and confusion. She was transported to the ED by her neighbor who assists with the history due to the patient's current state of confusion. The patient lives alone in her own apartment in an independent senior living facility and has noted a decreased ability to complete her daily activities due to her shortness of breath and fatigue. Her past medical history is positive for hypertension, urinary incontinence, chronic obstructive pulmonary disease, gastroesophageal reflux disease, and atrial fibrillation. Her home medications include: ranitidine $150 \mathrm{mg}$ by mouth twice daily, atenolol $50 \mathrm{mg}$ by mouth daily, ipratropium inhaler $1-2$ inhalations by mouth four times daily as needed, digoxin $0.125 \mathrm{mg}$ by mouth daily, warfarin $3 \mathrm{mg}$ by mouth daily, calcium carbonate/vitamin D $500 \mathrm{mg} / 200 \mathrm{IU}$ by mouth twice daily, and Tyelonol $\mathrm{PM}^{\circledR} 500 \mathrm{mg} / 25 \mathrm{mg}$ by mouth as needed for sleep. She is admitted for

submit your manuscript | www.dovepress.con 
chronic obstructive pulmonary disease (COPD) exacerbation and to rule out myocardial infarction. Her cognitive testing on admission reveals a Mini-Mental Status Examination (MMSE) score of 19/30 with deficits in orientation, attention, and recall. She scores positive on a Confusion Assessment Method (CAM) evaluation due to an acute change in mental status, disorganized thinking, and fluctuating attention.

\section{Introduction}

In 2005, there were more than 36 million Americans aged 65 and older. ${ }^{1}$ This population is known to suffer from multiple chronic diseases, require numerous prescribed and over-thecounter medications, and is at a higher risk of developing dementia. ${ }^{2-4}$ It is estimated that $20 \%-50 \%$ of the same cohort, including the four million with dementia, took at least one medication with some anticholinergic activities..$^{3,5-8}$

The use of drugs with anticholinergic activity has been an integral part of the routine treatment of common conditions such as asthma, urinary incontinence, and various psychiatric disorders. However, the adverse effects of these anticholinergics have been known for a long time including peripheral effects such as dry mouth and constipation, and central nervous system effects such as attention deficits and hallucinations. ${ }^{9}$ The central nervous system of older patients is very sensitive to the above adverse anticholinergic effects due to the significant decrease in cholinergic neurons or receptors in the brain of older adults, the reduction in hepatic metabolism and renal excretion of medications, and the increase in blood-brain barrier permeability. ${ }^{9}$

Many clinical researchers have recognized the importance of accounting for the risk of medications with central nervous system anticholinergic effects in the medical care of older patients, especially those with pre-existing cognitive disorders. ${ }^{3,9}$ However, there has been no systematic confirmation that acute or chronic prescribing of such medications leads to transient or permanent adverse cognitive outcomes. Thus, we conducted this systematic review of the literature to identify the various methods used to determine the central anticholinergic effects of various medications and evaluate the impact of such activities on cognitive function of older adults.

\section{Methods}

\section{Search strategies and study selection}

We searched the MEDLINE database using the search terms "cholinergic antagonists" combined with "delirium, dementia, amnestic, cognitive disorders." We limited our search to the English language and human studies published between January 1966 and January 2008. In order to identify pertinent studies, we scanned titles and abstracts from each retrieved citation. Publications that appeared to be irrelevant on the basis of the study population and methods as indicated in the title and abstract were discarded. We were also able to retrieve additional pertinent publications using the reference lists from identified articles.

\section{Inclusion criteria}

We included all cross-sectional, case control, and retrospective or prospective observational cohort studies that evaluated the anticholinergic activity of medications and their impact on the cognitive function of older adults. We excluded case study, case series, editorial, and review articles.

\section{Data extraction and synthesis}

We extracted data from each study that met our inclusion criteria into a pre-defined table that included: citation, anticholinergic activity measurement method, association between anticholinergics and cognitive impairment, total number of patients, and baseline demographics (eg, age, gender). Each article was critically evaluated in six categories for internal validity. Articles were evaluated on the parameters of the type of data included, adjustments for confounders, attrition rates, use of standardized cognitive assessment measures, and the presence of selection and recall bias. Each parameter evaluating internal validity was awarded a score of " 1 " if the study sufficiently met appropriate criteria and " 0 " if criteria were not met. Critical appraisal scores were then tabulated and correlated with a rating of "poor" if the appraisal score was 0-2; "fair" if the appraisal score was 3-4; and "good" if the score was 5-6. The critical appraisal was carried out by three clinical researchers (NC, MB, TL).

\section{Results}

Our search strategies revealed 258 potential articles from MEDLINE. However, after scanning the titles and the abstracts, we excluded 217 studies because they did not meet our inclusion criteria. An additional 20 of the remaining 41 articles were excluded because they were reviews, case reports, or case series. From the reference lists of the identified articles we were able to find six additional pertinent publications (see Figure 1).

In total, we found 27 studies that have investigated the cognitive burden of drugs with anticholinergic properties (see Table 1). All but seven studies were conducted among a heterogeneous group of participants in the United States. The remaining non-US studies were conducted among French, 


\section{Medline search result: 258 articles

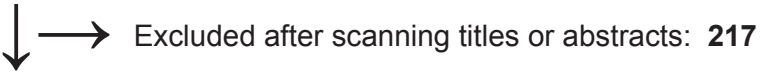 \\ Relevant studies: $\mathbf{4 1}$ \\ $\downarrow \longrightarrow$ Excluded reviews, case-reports, case-series: 20 \\ Included studies: $\mathbf{2 1}$ \\ $\downarrow \longleftarrow$ Included from reference lists: 6 \\ Total studies: 27}

Figure I Selection process for study inclusion.

Canadian, German, and Portuguese patients, but published in the English language. The majority of the studies included in this review took place in a hospitalized or nursing home population ( $\mathrm{n}=18)$, with the remaining studies $(\mathrm{n}=9)$ evaluating ambulatory patients. Of the 27 studies, 13 were designed as cross-sectional, six studies were case-control, and eight were prospective or retrospective cohort studies.

The anticholinergic activity of medications was evaluated using the serum anticholinergic activities assay (SAA) or the practitioner's knowledge of a list of drugs with known anticholinergic effects (see Table 2). SAA was the main method to determine anticholinergic activity in 17 studies. SAA is usually measured using a radio receptor competitive binding assay developed by Tune and Coyle. ${ }^{10}$ The SAA estimates anticholinergic activity generated not only from medications, but also from endogenous factors as a result of stress or hyperthermia. ${ }^{11}$ The other remaining studies combined clinical knowledge with drug lists to determine the anticholinergic activity of certain medications.

\section{Acute anticholinergic effect on cognition}

Delirium (acute and severe cognitive impairment) was diagnosed clinically using the DSM-IV criteria or using their derivatives, such as the Confusion Assessment Method (CAM), or its counterpart validated in the critically-ill population, the CAM-ICU. The CAM or CAM-ICU is a highly sensitive and specific method that evaluates subjects for the presence of four items: acute onset of cognitive changes fluctuating in course, inattention, disorganized thinking, and altered level of consciousness. ${ }^{36}$ The presence of the first two items and any of the third or fourth items determines the diagnosis of delirium. Other tools evaluating concentration, wakefulness, orientation, perception, and sleep disturbances (Saskatoon Delirium Checklist [SDC]) were used to evaluate delirium. The $\mathrm{SDC}^{11}$ and Delirium Symptoms Interview $(\mathrm{DSI})^{37}$ were both validated tools developed from the DSM criteria to measure cognitive deficits.

Thirteen studies evaluated the impact of anticholinergic on delirium, with eleven studies identifying a positive association between the use of such medicines and delirium. Delirium episodes experienced by study participants occurred at any point in the observation period(commonly the duration of inpatient admission). Few studies evaluated sequential blood samples to measure changes in SAA over time. Nearly $70 \%$ of the studies included in our analysis used SAA as the method for evaluating anticholinergic activity and $70 \%$ used either CAM or DSM criteria for evaluating delirium.

A recent study included in the analysis reported by Plaschke and colleagues evaluated a critically-ill population for the correlation of SAA or electroencephalography (EEG) with delirium. ${ }^{32}$ The authors report that a higher SAA value was identified in the delirious cohort, though this did not correlate with a difference in the risk of developing delirium in the ICU. Additionally, an article published in 1994 by Marcantonio and colleagues failed to draw a correlation between anticholinergic and postoperative delirium risk, though the anticholinergic exposure was only documented in $9 \%$ of the study population. ${ }^{24}$

\section{Chronic anticholinergic effect on cognition}

Chronic cognitive deficit was defined as mild cognitive impairment, worsening dementia or new diagnosis of dementia, or global decline in cognition not caused by delirium. Cognitive performance was evaluated using the MMSE in most studies included in this review and found an association between the use of anticholinergic and cognitive performance as determined by the MMSE (Table 3). This screening tool for cognition evaluates different areas of cognition such as orientation, memory, recall, attention, and language. Any score above 24, out of a possible score of 30 , is considered normal, while a score below 24 suggests a cognitive impairment. ${ }^{38}$ A modified version of the MMSE, the telephone interview for cognitive status (TICS_, has also been also used. The TICS is as reliable and valid as the MMSE. ${ }^{39}$ 
Table I Clinical studies evaluating anticholinergic activity

\begin{tabular}{|c|c|c|c|c|}
\hline Reference & Design & Setting & Sample size/Mean age & Critical appraisal* \\
\hline Ancelin et $\mathrm{al}^{12}$ & Longitudinal cohort & 63 general practices & $372 / 80$ & Good \\
\hline Bottigi et $\mathrm{al}^{13}$ & Longitudinal cohort & $\begin{array}{l}\text { Patients from Aging Alzheimer's } \\
\text { Disease Research Center }\end{array}$ & $592 / 73$ & Fair \\
\hline Caeiro et $\mathrm{al}^{14}$ & Case-control & Stroke patients from Neurology & $74 / 65$ & Good \\
\hline Chew et al ${ }^{15}$ & Cross-sectional & $\begin{array}{l}\text { Psychiatric and geriatric clinic } \\
\text { inpatients }\end{array}$ & $26 / 83.6$ & Fair \\
\hline Flacker et $\mathrm{al}^{16}$ & Cross-sectional & Acutely ill medical inpatients & $67 / 85$ & Good \\
\hline Flacker et $\mathrm{al}^{17}$ & Cross-sectional & $\begin{array}{l}\text { Nursing home residents with } \\
\text { fever }\end{array}$ & $22 / 88$ & Good \\
\hline Golinger et al ${ }^{18}$ & Longitudinal cohort & Surgical Intensive care unit & $25 / 58$ & Poor \\
\hline Han et al ${ }^{19}$ & Longitudinal cohort & $\begin{array}{l}\text { Hospitalized patients with } \\
\text { delirium }\end{array}$ & $278 / 83$ & Good \\
\hline Hilmer et $\mathrm{a}^{20}$ & Cross-sectional & Community-based & $3075 / 73$ & Good \\
\hline Lechevalier et $\mathrm{al}^{21}$ & Cross-sectional & Community-based & I780/77 & Good \\
\hline Lu et $\mathrm{a}^{22}$ & Longitudinal cohort & Community-based & $69 / 76$ & Good \\
\hline Mach et $\mathrm{a}^{23}$ & Case-control & VA hospital medical units & $22 / 71$ & Fair \\
\hline Marcantonio et $\mathrm{al}^{24}$ & Cross-sectional & Post-surgical patients & $91 / 73$ & Good \\
\hline Miller et $\mathrm{a}^{25}$ & Longitudinal cohort & Surgical patients & $30 / 67$ & Good \\
\hline Minzenberg et $\mathrm{a}^{26}$ & Cross-sectional & $\begin{array}{l}\text { Outpatients from VA medical } \\
\text { center }\end{array}$ & $106 / 40$ & Fair \\
\hline Mondimore et $\mathrm{al}^{27}$ & Cross-sectional & Post-ECT inpatients & $20 / 49$ & Fair \\
\hline Mulsant et $a l^{6}$ & Cross-sectional & Community patients & $20 I / 78$ & Good \\
\hline Mussi et $\mathrm{a}^{28}$ & Cross-sectional & Geriatric inpatients & $61 / 79$ & Fair \\
\hline Nebes et $\mathrm{a}^{29}$ & Cross-sectional & Psychiatric and geriatric inpatients & $36 / 69$ & Fair \\
\hline Nebes et $\mathrm{al}^{30}$ & Cross-sectional & Community based & $134 / 75$ & Fair \\
\hline Patten et $\mathrm{al}^{31}$ & Case-control & Psychiatric inpatients & $425 / 65$ & Fair \\
\hline Plaschke et $\mathrm{al}^{32}$ & Longitudinal cohort & $\begin{array}{l}\text { Medical and surgical intensive } \\
\text { care unit with delirium }\end{array}$ & $37 / 64$ & Fair \\
\hline Roe et $\mathrm{al}^{33}$ & Case-control & Community-based & $836 / 75$ & Fair \\
\hline Rovner et a $\left.\right|^{34}$ & Cross-sectional & Nursing home patients & $22 / 81$ & Fair \\
\hline Thienhaus et $\mathrm{a}^{35}$ & Case-control & $\begin{array}{l}\text { Psychiatric and geriatric } \\
\text { inpatients }\end{array}$ & $28 / 65$ & Fair \\
\hline Tollefson et $\mathrm{al}^{5}$ & Case-control & Nursing home patients & $34 / 79$ & Good \\
\hline Tune et $\mathrm{a}^{10}$ & Longitudinal cohort & Cardiac surgery patients & $29 / 55$ & Fair \\
\hline
\end{tabular}

Abbreviations: VA, Veteran Administration; ECT, electro-convulsive therapy.

Notes: *Articles were appraised on the following criteria: inclusion of longitudinal data; adjustments for age, gender, baseline cognition, or other relevant parameters; attrition rate $<40 \%$; use of standardized measurements for cognition and delirium; minimum selection bias; and minimum recall bias.

Few studies evaluated for any long-term ( $>12$ months) impact on cognitive function in patients exposed to anticholinergic. Ancelin and colleagues ${ }^{12}$ provided one of the few studies evaluating the impact of anticholinergic over time. This study included a French population without baseline cognitive deficits and found an increased risk of mild cognitive impairment at the one-year follow-up based on criteria established by the Stockholm consensus group. However, at eight years of followup the authors did not find an increased risk in the diagnosis of dementia (DSM-III) between consistent users of anticholinergic and nonusers. Another study by $\mathrm{Lu}$ and colleagues ${ }^{22}$ revealed no impact of anticholinergic exposure on cognition among a group of patients with baseline cognitive impairment at one year, though a significant decrease in cognitive function at two years was noticed in those using anticholinergics.

\section{Clinical interpretation of data synthesis}

Our systematic evidence review of 27 studies found a consistent association between the use of anticholinergic and cognitive 
Table 2 Association between serum anticholinergic activities and cognition

\begin{tabular}{|c|c|c|}
\hline Reference & Cl & Delirium \\
\hline Ancelin et a $\left.\right|^{12}$ & $\begin{array}{l}+ \\
\text { (Stockholm) }\end{array}$ & $\mathrm{N} / \mathrm{A}$ \\
\hline Chew et al ${ }^{15 *}$ & $\begin{array}{l}+ \\
\text { (MMSE, SIB) }\end{array}$ & $\mathrm{N} / \mathrm{A}$ \\
\hline Flacker et al ${ }^{16}$ & $\mathrm{~N} / \mathrm{A}$ & $\begin{array}{l}+ \\
(\mathrm{CAM}, \mathrm{DSI})\end{array}$ \\
\hline Flacker et $\mathrm{al}^{17}$ & N/A & $\begin{array}{l}+ \\
\text { (CAM) }\end{array}$ \\
\hline Golinger et al ${ }^{18}$ & $\mathrm{~N} / \mathrm{A}$ & $\begin{array}{l}+ \\
\text { (DSM-III) }\end{array}$ \\
\hline Mach et $\mathrm{a}^{23}$ & N/A & $\begin{array}{l}+ \\
(\text { DSM-III-R) }\end{array}$ \\
\hline Miller et $\mathrm{a}^{25}$ & $\begin{array}{l}- \\
\text { (MMSE) }\end{array}$ & $\begin{array}{l}+ \\
(\mathrm{SDC})\end{array}$ \\
\hline Mondimore et $\mathrm{al}^{27}$ & $\begin{array}{l}+ \\
\text { (MMSE) }\end{array}$ & $\mathrm{N} / \mathrm{A}$ \\
\hline Mulsant et $\mathrm{al}^{6}$ & $\begin{array}{l}+ \\
\text { (MMSE) }\end{array}$ & $\mathrm{N} / \mathrm{A}$ \\
\hline Mussi et $\mathrm{a}^{28}$ & $\mathrm{~N} / \mathrm{A}$ & $\begin{array}{l}+ \\
(\mathrm{CAM})\end{array}$ \\
\hline Nebes et $\mathrm{a}^{29}$ & $\begin{array}{l}+ \\
(\mathrm{DSM}-\mathrm{IV})\end{array}$ & $\mathrm{N} / \mathrm{A}$ \\
\hline Nebes et $\mathrm{al}^{30}$ & $\begin{array}{l}+ \\
\text { (Verbal N Back test) }\end{array}$ & $\mathrm{N} / \mathrm{A}$ \\
\hline Plaschke et al ${ }^{32}$ & $N / A$ & $\begin{array}{l}- \\
(\mathrm{CAM}-\mathrm{ICU})\end{array}$ \\
\hline Rovner et $\mathrm{al}^{34 *}$ & $\begin{array}{l}+ \\
\text { (MMSE, DSM-III) }\end{array}$ & $\mathrm{N} / \mathrm{A}$ \\
\hline Thienhaus et $\mathrm{al}^{35 *}$ & $\begin{array}{l}+ \\
\text { (MMSE) }\end{array}$ & $\mathrm{N} / \mathrm{A}$ \\
\hline Tollefson et al ${ }^{5 *}$ & $\begin{array}{l}+ \\
\text { (MMSE, BCRS,WMS) }\end{array}$ & $\begin{array}{l}+ \\
(\mathrm{SDC})\end{array}$ \\
\hline Tune et al ${ }^{10}$ & N/A & $\begin{array}{l}+ \\
\text { (Clinical) }\end{array}$ \\
\hline
\end{tabular}

Abbreviations: $\mathrm{Cl}$, cognitive impairment, includes mild cognitive impairment $(\mathrm{MCl})$, or worsening function in those with baseline diagnosis of $\mathrm{Cl}$; "+": statistically significant association; “-”: no significant association; “N/A": not assessed; Stockholm, Stockholm consensus group criteria for diagnosing mild cognitive impairment; SAA, serum anticholinergic activity; MMSE, Mini-Mental State Exam; SIB, severe impairment battery; TMT, Trail Making Test; WLMT, Word List Memory Test; BCRS, Brief Cognitive Rating Scale; WMS, Wechsler Memory Scale; SDC, Saskatoon Delirium Checklist; CAM, Confusion Assessment Method; DSI, Delirium Symptom Interview; DI, Delirium Index; IST, Isaacs' Set Test; BVRT, Benton Visual Retention Test; DRS, Dementia Rating Scale; DSST, Digit Symbol Substitution Test (derived from the WMS).

Note: *Indicates the study population had baseline cognitive impairment.

impairment in older adults, including delirium. Our findings were similar to a review of 80 studies that was conducted by Dyer and colleagues ${ }^{40}$ that found a positive association between the use of anticholinergic drugs and postoperative delirium. Furthermore, Tune and colleagues also correlated delirium and confusional states in demented patients as a result of anticholinergic activities. ${ }^{10}$ The authors noted that this adverse effect may not arise exclusively from an individual agent with strong anticholinergic effects, but as an accumulation of multiple medications with varying degrees of anticholinergic effects. Similarly, the anticholinergic effects seem not to be related to the dosage of each individual drug, identifying the role of other factors in the development of cognitive deficits. ${ }^{41}$ The presence of multiple baseline risk factors as well as the role of multiple neurotransmitter systems in the development of d elirium or cognitive impairment has been previously described. ${ }^{42}$

The finding of this systematic review indicates the burden of anticholinergic has consistently been shown to negatively associate with cognitive performance. All but two studies ${ }^{31}$ included in this review support the association of anticholinergic use and worsening cognitive performance either through an acute (delirium) or chronic (mild cognitive impairment) impact. The long-term effect of anticholinergics on cognition requires further analysis, as few studies adequately quantified exposure to anticholinergics and correlated this exposure to long-term risks of developing a neurodegenerative dementing disorder such as Alzheimer disease.

The studies included in this evaluation draw a consistent correlation between SAA and worsening performance on cognitive testing. Throughout the studies evaluated in this review, investigators discovered minimal changes in global measures of cognitive function with exposure to anticholinergics, and instead identified deficits in processing speed, psychomotor performance, concentration/attention, problem solving and language skills. Delirium was frequently identified by disorientation, altered consciousness, disorganized thinking, and fluctuating alertness. Variable deficits in recall were identified, with some articles describing deficits in verbal or narrative recall, with others identifying no change in recall abilities. The significance of this comparison is that in a clinical setting many practitioners rely on global measures to evaluate cognitive performance and therefore may not accurately identify a decline in cognitive function when evaluating exposure to anticholinergics.

Most studies identified in our review have used the in vitro SAA, while few studies have used drug lists coupled with clinical judgment. ${ }^{6}$ All of these different methods have limitations, such as the inability to assess anticholinergic effects of each individual drug or to determine their potential synergistic effects when combined. Although higher levels of SAA has been correlated with poor cognitive function in several previous studies, conflicting data exists that makes 
Table 3 Association between anticholinergic activity assessed by expert-based drug list and cognition

\begin{tabular}{|c|c|c|}
\hline Reference & Cl & Delirium \\
\hline Bottigi et al'3 & $\begin{array}{l}+ \\
\text { (MMSE,TMT,WLMT) }\end{array}$ & $\mathrm{N} / \mathrm{A}$ \\
\hline Caeiro et $\mathrm{al}^{14}$ & $\mathrm{~N} / \mathrm{A}$ & $\begin{array}{l}+ \\
\text { (DSM-IV-TR) }\end{array}$ \\
\hline Han et $\mathrm{al}^{19}$ & $\mathrm{~N} / \mathrm{A}$ & $\begin{array}{l}+ \\
\text { (DI) }\end{array}$ \\
\hline Hilmer et $\mathrm{a}^{20}$ & $\begin{array}{l}+ \\
(\mathrm{DSST})\end{array}$ & $N / A$ \\
\hline Lechevalier et $\mathrm{a}^{21}$ & $\begin{array}{l}+ \\
(\mathrm{MMSE}, \mathrm{BVRT}, \mathrm{IST})\end{array}$ & $N / A$ \\
\hline Lu et $\mathrm{al}^{22 *}$ & $\begin{array}{l}+ \\
\text { (MMSE, DRS) }\end{array}$ & N/A \\
\hline Marcantonio et $\mathrm{al}^{24}$ & $\mathrm{~N} / \mathrm{A}$ & $\begin{array}{l}- \\
\text { (CAM) }\end{array}$ \\
\hline Minzenberg et $\mathrm{a}^{26}$ & $\begin{array}{l}+ \\
(\mathrm{WMS})\end{array}$ & $N / A$ \\
\hline Patten et a ${ }^{31}$ & $\mathrm{~N} / \mathrm{A}$ & $\begin{array}{l}+ \\
\text { (DSM-IV) }\end{array}$ \\
\hline Roe et $\mathrm{al}^{33 *}$ & $\begin{array}{l}+ \\
\text { (Initiation of Donepezil therapy) }\end{array}$ & N/A \\
\hline
\end{tabular}

Abbreviations: $\mathrm{Cl}$, cognitive impairment, includes mild cognitive impairment ( $\mathrm{MCl})$, or worsening function in those with baseline diagnosis of Cl; “+”: statistically significant association; "-": no significant association; "N/A": not assessed; MMSE, Mini-Mental State Exam; TMT, Trail Making Test; WLMT, Word List Memory Test; DSM-IV-TR, Diagnostic and Statistical Manual of Mental Disorders, 4th Edition; WMS, Wechsler Memory Scale; CAM, Confusion Assessment Method; IST, Isaacs' Set Test; BVRT, Benton Visual Retention Test; DRS, Dementia Rating Scale; DSST, Digit Symbol Substitution Test (derived from the WMS).

Note: *Indicates the study population had baseline cognitive impairment.

interpretation of the absolute SAA value difficult. Similarly, the complexity of the testing procedure, along with the intermittent availability, limits the widespread acceptance as a biomarker or predictor of delirium. Many existing medication scales compute a total score of different drugs to determine the anticholinergic burden, suggesting that special attention should be paid not only to individual drug score, but also to the accumulated anticholinergic effects of all medications taken by the patient. Carnahan and colleagues ${ }^{41}$ have established a tool, the anticholinergic drug scale (ADS), divided in an ordinal fashion from 0 to 3 , with 0 signifying no known anticholinergic activity, and 3 signifying marked anticholinergic activity. They found that ADS total scores were significantly associated with SAA. However, Thomas and colleagues failed to prove a correlation between SAA and a clinical diagnosis of delirium in older patients ( $>$ age 80 years) with acute illness. ${ }^{43}$ Their results suggest the SAA is limited to peripheral activity, not central anticholinergic effects that may impact cognition.
The main limitation of this review is in the selection of studies with different designs and settings that contribute to the common conclusion. This review also bears limitations inherent to each study design, whether it is a cross-sectional, a case-control or a longitudinal study. Given the heterogeneity in the included studies and populations, baseline confounders such as cognitive impairment, past medical history and reason for admissions could not be evaluated and may impact results. The heterogeneity in study populations of the included studies may have significantly affected results. It is well documented that endogenous cholinergic neurotransmitter shifts may impact cognition, ${ }^{44,45}$ as well as normal responses to stress that may play a role in cognitive testing. Similarly, reporting mechanisms for the medications evaluated in the included studies was inconsistent, making the generation of a comprehensive, clinically useful list of anticholinergic medications impractical from this data set. Although central anticholinergic activity is most relevant in the development of delirium, cognitive impairment, or dementia, no study stratified medications by peripheral or central activity.

Through our search strategy, it is possible to miss a small number of studies that are unpublished. All but two studies assessed either acute cognitive impairment or delirium, with few studies measuring long-term effects on cognition. Moreover, methods used to diagnose delirium were not consistent throughout the included studies. The diagnostic criteria for delirium have evolved over time; thus the reviewed studies present a variety of methods to measure the diagnosis. Despite these limitations, this study is the first comprehensive review of the measurement and cognitive impact of anticholinergic medications.

\section{Gaps in the literature}

Despite the associations that have been previously described regarding the impact of anticholinergics on cognitive function, several gaps in the existing literature can still be identified. First, our existing literature support for the association of anticholinergics and cognitive impairment lacks randomized, prospective clinical trials that describe a presumed difference in relevant outcomes. It remains to be sufficiently determined what outcomes should be expected if a reduction in anticholinergic activity is achieved in various populations with and without cognitive impairment. One might speculate that frequency and severity of acute or chronic mental status changes be reduced when the burden of anticholinergic medications is reduced, though the extent or duration of exposure minimization required to achieve a clinically significant impact remains to be delineated. 
Secondly, the correlation of exposure to anticholinergics and health-related outcomes remains to be described. Many literature sources included in this review have drawn associations between anticholinergics use and cognitive impairment; however, no data source has evaluated an impact on hospitalization rates, emergency department visits, duration of hospital stay, overall quality of life, or even mortality.

Finally, long-term exposure to medications with anticholinergic activity was not evaluated in a majority of the studies. The impact of anticholinergics on cognitive impairment was often limited to short-term exposure, with limited assessment of medication regimens or SAA values. The impact of longterm exposure to medications with anticholinergic medica- tions remains to be sufficiently examined, as in the PAQUID study of community-dwelling elders in southern France. ${ }^{21}$ Similarly, a recent study by Boustani and colleagues suggests an increased risk of incident cognitive impairment in African-Americans consistently using $\mathrm{H}-2$ receptor antagonists over a five-year observation period. ${ }^{46}$ This warrants further study into the impact of chronic exposure to anticholinergic medications, the potential for this exposure to influence cognition over time, and the extent of exposure required to induce adverse cognitive outcomes.

We suggest the logical management of anticholinergics use as described in Figure 2. As illustrated in this review, the elderly population, and specifically those experiencing

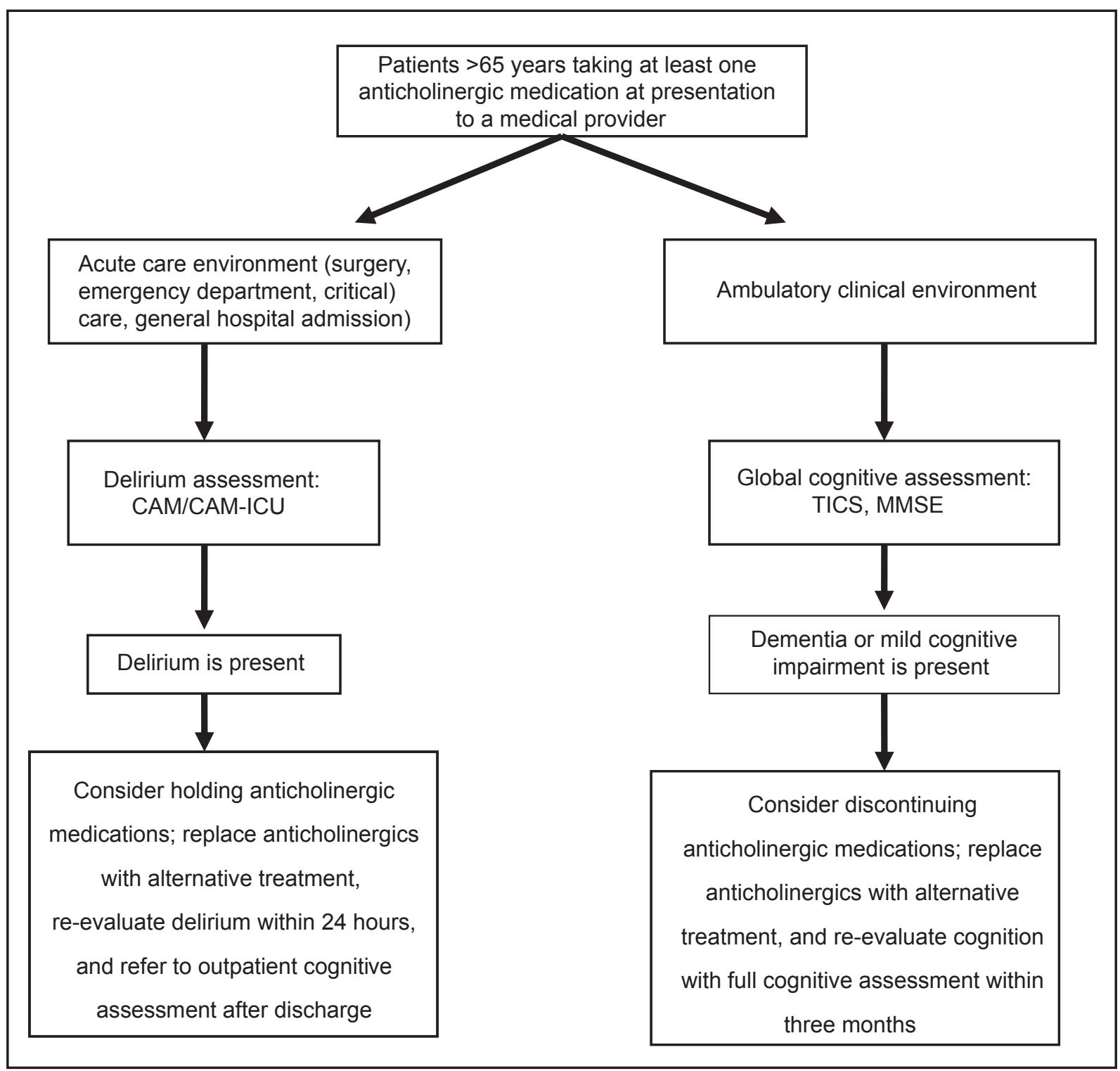

Figure 2 Proposed algorithm for the clinical approach to older adults prescribed anticholinergic medications. Abbreviations: CAM, Confusion Assessment Method; TICS, telephone interview for cognitive status; MMSE, Mini-Mental Status Exam. 
an acute illness, is uniquely sensitive to the central anticholinergic adverse effects of medications and should be closely monitored for the development of unwanted adverse effects on cognition. Recognizing patients at risk due to exposure of anticholinergics should warrant cognitive evaluation not only in acute care environments, but also ambulatory environments when subjective complaints of cognitive impairment supplement clinical suspicion. In clinical practice situations where anticholinergic cognitive adverse effects are suspected, the course of action might be to consider the withdrawal of potentially offending medication(s). Although the expected clinical impact on cognitive deficits with a reduction in anticholinergic burden remains to be sufficiently studied, removal of potentially harmful medications in lieu of equally effective alternatives with lower anticholinergic activity might be a good practice.

\section{Scenario resolution}

During the hospitalization, the patient received a geriatrics consultation and her anticholinergics burden was reduced by discontinuing ranitidine, oxybutynin, diphenhydramine, and digoxin. Ranitidine was replaced with esomeprazole, Tylenol $\mathrm{PM}^{\circledR}$ was replaced with acetaminophen as needed, and no replacements were instituted for oxybutynin and digoxin. Other medications with notable systemic anticholinergic properties, warfarin and atenolol, were continued during the hospital stay and at discharge. The patient's delirium resolved within 48 hours of hospital admission due to either resolving medical illness or a reduction of anticholinergic burden. Repeat MMSE was not performed, though follow-up for further cognitive testing was arranged within four weeks after discharge, where mild cognitive impairment was identified and the patient continues to follow in the geriatric clinic for appropriate monitoring of cognitive function.

\section{Conclusion}

In a world facing an exponential growth of older patients, high prevalence of multiple chronic disease and substantial use of numerous medications, the integration of a routine recognition of the anticholinergic cognitive effects of medications into the care of hospitalized older adults may have the potential to improve patient and health care-related outcomes.

\section{Acknowledgments}

Supported by Grant (K23 AG 26770-01) from the John A. Hartford Foundation, the Atlantic Philanthropies, the Starr
Foundation, and the National Institute on Aging. The authors report no conflicts of interest in this work.

\section{References}

1. United States Census Bureau. Nation's Population One-Third Minority. May 10, 2009. Accessed on Feb 10, 2009. Available from: http://www. census.gov/Press-Release/www/releases/archives/population/ 006808.html.

2. Wolff JL, Starfield B, Anderson G. Prevalence, expenditures, and complications of multiple chronic conditions of the elderly. Arch Intern Med. 2002;162:2269-2276.

3. Schubert CC, Boustani M, Callahan CM, et al. Comorbidity profile of dementia patients in primary care: Are they sicker? JAGS. 2006;54(1): 104-109.

4. Boustani M, Peterson B, Hanson L, Harris R, Krasnov C. Screening for Dementia. Systematic Evidence Review. Rockville, MD: Agency for Healthcare Research and Quality; 2003. Available from: http://www. ahrq.gov/clinic/uspstfix.htm.

5. Tollefson GD, Montague-Clouse J. The relationship of serum anticholinergic activity to mental status performance in an elderly nursing home population. J Neuropsychiatry Clin Neurosci. 1991;3(3): 314-319.

6. Mulsant BH, Pollock BG, Kirshner M, Shen C, Hiroko D, Ganguli M. Serum anticholinergic activity in a community-based sample of older adults. Arch Gen Psychiatry. 2003;60:198-203.

7. Blazer DG 2nd, Federspiel CF, Ray WA, et al. The risk of anticholinergic toxicity in the elderly: a study of prescribing practices in two populations. J Gerontol. 1983;38:31-35.

8. Wimo A, Winblad B, Jonsson L. An estimate of the total worldwide societal costs of dementia in 2005. Alzheimer and Dementia. 2007;3:81-921.

9. Tune LE. Anticholinergic effects of medications in elderly patients. J Clin Psychiatry. 2001;62(21):11-14.

10. Tune LE, Damlouji NF, Holland A, Gardner TJ, Folstein MF, Coyle JT. Association of postoperative delirium with raised serum levels of anticholinergic drugs. Lancet. 1981;2(8248):651-653.

11. Miller PS, Richardson JS, Jyu CA, et al. Association of low serum anticholinergic levels and cognitive impairment in elderly presurgical patients. Am J Psychiatry. 1988; 145:342-345.

12. Ancelin ML, Artero S, Portet F, Dupuy AM, Touchon J, Rithie K. Non-degenerative mild cognitive impairment in elderly people and use of anticholinergic drugs: longitudinal cohort study. BMJ. 2006;332(7539):455-459.

13. Bottigi KA, Salazar JC, Yu L, Caban-Holt AM, Ryan M, Mendiondo MS, Schmitt FA. Long-term cognitive impact of anticholinergic medications in older adults. Am J Geriatr Psychiatry. 2006;14(11):980-984.

14. Caeiro L, Ferro JM, Claro MI, Coelho J, Albuquerque R, Figueira ML. Delirium in acute stroke: a preliminary study of the role of anticholinergic medications. Eur J Neurol. 2004;11:699-704.

15. Chew ML, Musant BH, Pollock BG. Serum anticholinergic activity and cognition in patients with moderate-to-severe dementia. Am J Geriatr Psychiatry. 2005;13:5354-538.

16. Flacker JM, Virginia C, Mach JR, Bettin K, Kiely DK, Wei J. The association of serum anticholinergic activity with delirium in elderly medical patients. Am J Geriatr Psychiatry. 1998;6:31-41.

17. Flacker JM, Lipsitz LA. Serum anticholinergic activity changes with acute illness in elderly medical patients. J Gerontol A Biol Sci Med Sci. 1999;54(1):M12-M16.

18. Golinger RC, Peet T, Tune LE. Association of elevated plasma anticholinergic activity with delirium in surgical patients. Am J Psychiatry. 1987;144(9):1218-1220.

19. Han L, McCusker J, Cole M, Abrahamowicz M. Use of medications with anticholinergic effect predicts clinical severity of delirium symptoms in older medical inpatients. Arch Intern Med. 2006;161:1099-1105.

20. Hilmer SN, Mager DE, Simonsick EM, et al. A Drug Burden Index to define the functional burden of medications in older people. Arch Intern Med. 2007;167:781-787. 
21. Lechevallier-Michel N, Molimard M, Dartigues JF, Fagrigoule C, Fourrrier-Reglat A. Drugs with anticholinergic properties and cognitive performance in the elderly: results from the PAQUID study. Br J Clin Pharmacol. 2004;59(2):143-151.

22. Lu CJ, Tune LE. Chronic exposure to anticholinergic medications adversely affects the course of Alzheimer disease. Am J Geriatr Psychiatry. 2003;11(4):458-461.

23. Mach JR Jr, Dysken MW. Serum anticholinergic activity in hospitalized older persons with delirium: a preliminary study. J Am Geriatr Soc. 1995;43(5):491-495.

24. Marcantonio ER, Juarez G, Goldman L, et al. The relationship of postoperative delirium with psychoactive medications. JAMA. 1994;272(19): 1518-1522.

25. Miller PS, Richardson JS, Jyu CA, Lemay JS, Hiscock M, Keegan DL. Association of low serum anticholinergic levels and cognitive impairment in elderly presurgical patients. Am J Psychiatry. 1988;145(3):342-345.

26. Minzenberg MJ, Poole JH, Benton C, Vinogradov S. Association of anticholinergic load with impairment of complex attention and memory in schizophrenia. Am J Psychiatry. 2004;161:116-124.

27. Mondimore FM, Damlouji N, Folstein MF, Tune L. Post-ECT confusional states associated with elevated serum anticholinergic levels. Am J Psychiatry. 1983;140(7):930-931

28. Mussi C, Ferrari R, Ascari S, Salvioli G. Importance of serum anticholinergic activity in the assessment of elderly patients with delirium. J Geriatr Psychiatry Neurol. 1999;12(2):82-86.

29. Nebes RD, Pollock BG. Low-level serum anticholinergicity as a source of baseline cognitive heterogeneity in geriatric depressed patients. Psychopharmacol Bull. 1997;33(4):715-720.

30. Nebes RD Pollock BG, Meltzer CC, et al. Serum anticholinergic activity, white matter hyperintensities, and cognitive performance. Neurology. 2005;65:1487-1489.

31. Patten SB. Delirium in psychiatric inpatients: a case-control study. Can J Psychiatry. 2001;46:162-166.

32. Plaschke K, Hill H, Engelhardt R, et al. EEG changes and serum anticholinergic activity measured in patients with delirium in the intensive care unit. Anaesthesia. 2007;62:1217-1223.

33. Roe CM, Anderson MJ, Spivack B. Use of anticholinergic medications by older adults with dementia. JAGS. 2002;50:836-842.
34. Rovner BW, David A, Lucas-Blaustein MJ, Conklin B, Filipp L, Tune L. Self-care capacity and anticholinergic drug levels in nursing home patients. Am J Psychiatry. 1988;145(1):107-109.

35. Thienhaus OJ, Allen A, Bennett JA. Anticholinergic serum levels and cognitive performance. Eur Arch Psychiatry Clin Neurosci. 1990;240(1):28-33.

36. Inouye SK, van Dyck CH, Alessi CA, Balkin S, Siegal AP, Horwitz RI. Clarifying confusion: the confusion assessment method. A new method for detection of delirium. Ann Intern Med. 1990;113:941-948.

37. Albert MS, Levkoff SE, Reilly C, et al. The Delirium Symptom Interview: an interview for the detection of delirium symptoms in hospitalized patients. J Geriatr Psychiatry Neurol. 1992; 5:14-21.

38. Folstein MF, Folstein SE, McHugh PR. "Mini-Mental State:” A practical method for grading the cognitive state of patients for the clinician. J Psychiatry Res. 1975;12:189-198.

39. Brandt JS, Folstein M. The telephone interview for cognitive status. Neuropsychiatry Neuropsychol Behav Neurol. 1988;1(2):111-117.

40. Dyer CB, Ashton C, Teasdale TA. Postoperative delirium: a review of 80 primary data-collection studies. Arch Intern Med. 1995;155(5): 461-465.

41. Carnahan RM, Lund BC, Perry PJ, Pollock BG, Culp KR. The Anticholinergic Drug Scale as a measure of drug-related anticholinergic burden: Association with Serum Anticholinergic Activity. J Clin Pharmacol. 2006;46:1481-1486.

42. Trzepacz PT. The neuropathogenesis of delirium. Psychosomatics. 1994;4:374-391.

43. Thomas C, Hesterman U, Kopitz J, et al. Serum anticholinergic activity and cerebral cholinergic dysfunction: An EEG study in frail elderly with and without delirium. BMC Neuroscience. 2008;9(86):1-10.

44. Dixon CE, Bao J, Bergmann JS, Johnson KM. Traumatic brain injury reduces hippocampal high-affinity $[3 \mathrm{H}]$ choline uptake but not extracellular choline levels in rats. Neurosci Lett. 1994;180:127-130.

45. Dixon CE, Hamm RJ, Taft WC, Hayes RL. Increased anticholinergic sensitivity following closed skull impact and controlled cortical impact traumatic brain injury in the rat. J Neurotrauma. 1994;11:275-287.

46. Boustani M, Hall KS, Lane KA, Aljadhey H, Gao S, Unverzagt F, Murray MD, Ogunniyi A, Hendrie H. The association between cognition and histamine-2 receptor antagonists in African Americans. J Am Geriatr Soc. 2007;55(8):1248-1253.
Clinical Interventions in Aging

\section{Publish your work in this journal}

Clinical Interventions in Aging is an international, peer-reviewed journal focusing on evidence-based reports on the value or lack thereof of treatments intended to prevent or delay the onset of maladaptive correlates of aging in human beings. This journal is indexed on PubMed Central, MedLine, the American Chemical Society's 'Chemical

\section{Dovepress}

Abstracts Service' (CAS), Scopus and the Elsevier Bibliographic databases. The manuscript management system is completely online and includes a very quick and fair peer-review system, which is all easy to use. Visit http://www.dovepress.com/testimonials.php to read real quotes from published authors. 